\title{
Filament formation associated with spirochetal infection: a comparative approach to Morgellons disease
}

This article was published in the following Dove Press journal:

Clinical, Cosmetic and Investigational Dermatology

II November 20 I I

Number of times this article has been viewed

\section{Marianne J Middelveen Raphael B Stricker}

International Lyme and Associated Diseases Society, Bethesda, MD, USA
Correspondence: Raphael B Stricker 450 Sutter Street, Suite 1504, San Francisco, CA 94108, USA

$\mathrm{Tel}+\mathrm{I} 4 \mathbf{I 5} 399$ I035

Fax + I 4I5 3991057

Email rstricker@usmamed.com

\begin{abstract}
Bovine digital dermatitis is an emerging infectious disease that causes lameness, decreased milk production, and weight loss in livestock. Proliferative stages of bovine digital dermatitis demonstrate keratin filament formation in skin above the hooves in affected animals. The multifactorial etiology of digital dermatitis is not well understood, but spirochetes and other coinfecting microorganisms have been implicated in the pathogenesis of this veterinary illness. Morgellons disease is an emerging human dermopathy characterized by the presence of filamentous fibers of undetermined composition, both in lesions and subdermally. While the etiology of Morgellons disease is unknown, there is serological and clinical evidence linking this phenomenon to Lyme borreliosis and coinfecting tick-borne agents. Although the microscopy of Morgellons filaments has been described in the medical literature, the structure and pathogenesis of these fibers is poorly understood. In contrast, most microscopy of digital dermatitis has focused on associated pathogens and histology rather than the morphology of late-stage filamentous fibers. Clinical, laboratory, and microscopic characteristics of these two diseases are compared.
\end{abstract}

Keywords: Digital dermatitis, Morgellons disease, Lyme disease, Borrelia burgdorferi, spirochetes

\section{Introduction}

First described in 1974, bovine digital dermatitis (BDD), also known as papillomatous digital dermatitis, is an emerging infectious disease that causes lameness, decreased milk production, and weight loss in cattle. ${ }^{1,2}$ Since 1993, BDD has spread rapidly throughout the US, Europe, and Australia, becoming a significant cause of morbidity in dairy operations. ${ }^{3-5}$ The disease causes dermatitis and papillomatous lesions of the skin bordering the coronary band in the hooves of livestock, primarily cattle (Figure 1). ${ }^{3-5}$

Histologically, the lesions resemble those of yaws, which suggests spirochetal involvement, ${ }^{5,6}$ and cattle with BDD are reported to be serologically reactive to Borrelia burgdoferi antigens. ${ }^{7,8}$ Consistent detection of spirochetes in the lower dermal layers adds further weight to the etiological involvement of these bacterial agents. ${ }^{9-16}$ Proliferative or late-stage lesions demonstrate hyperkeratosis and proliferation of keratin filaments ${ }^{4}$ as well as elongated keratinocytes. ${ }^{17}$ The proliferation of keratin filaments that may reach several centimeters in length has led to the disease receiving descriptive common names, such as "hairy heel warts" (Figure 1). ${ }^{18}$

Morgellons disease is an emerging human dermatological disorder that parallels BDD in many aspects (Tables 1 and 2). In addition to a spirochetal association, 

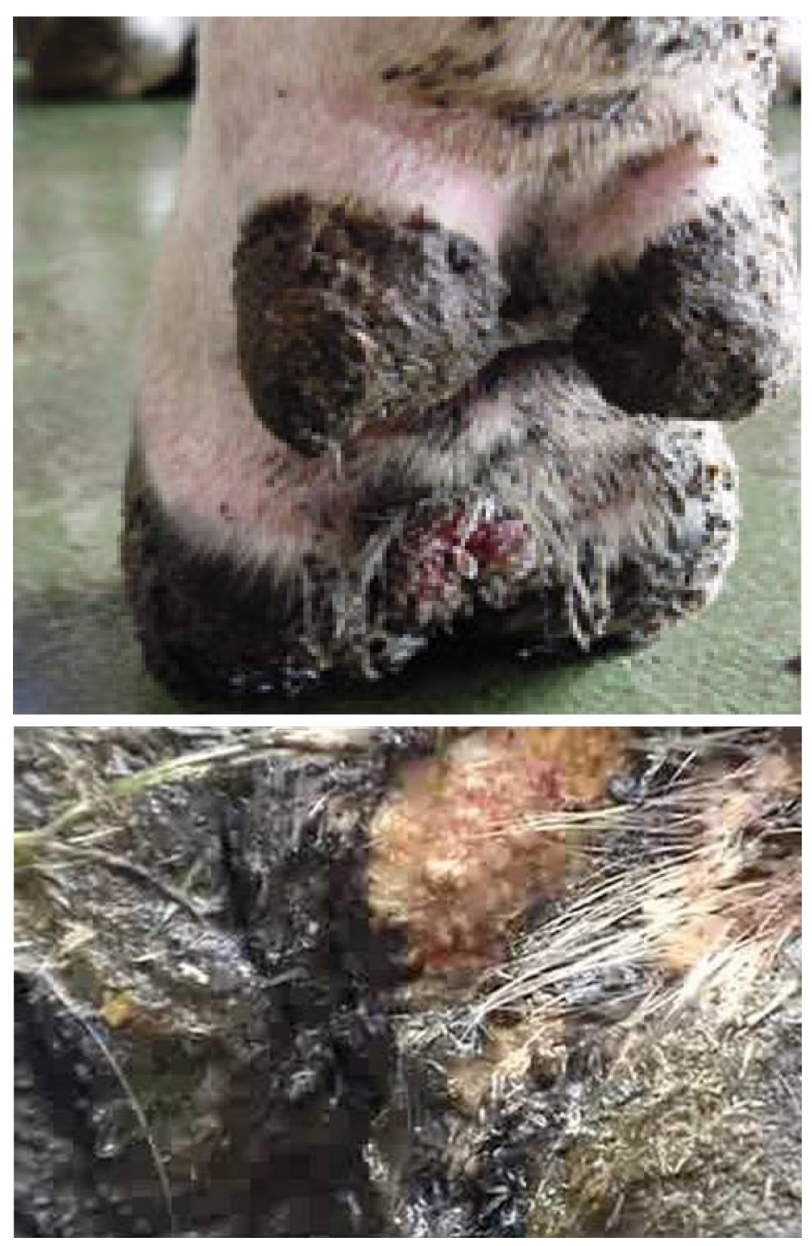

Figure I Bovine digital dermatitis. Note painful ulcerating lesion above the interdigital cleft of the hoof with multiple grayish fibers (top) and closer view of fibers (bottom). Photographs courtesy of GEA Farm Technologies, reprinted with permission.

Morgellons disease is characterized by dermatological lesions associated with filament formation (Figure 2). Symptoms such as fatigue, neurological disorders, and joint pain suggest systemic involvement as well as dermopathy. ${ }^{19-22}$ Peripheral neuropathy, delayed capillary refill, abnormal Romberg's sign, decreased body temperature, tachycardia, elevated proinflammatory markers, and elevated insulin levels are reported to be objective clinical evidence of the disease. ${ }^{23}$

The hallmark of Morgellons disease is "mysterious" fibers of unknown etiology, easily visualized with the aid of a $60 \times$ hand-held digital microscope, that appear both in nonhealing or slow-healing skin lesions and beneath unbroken skin (Figure 2). The fibers resist extraction, and attempts to remove them may cause shooting pain. Patients with the affliction may experience crawling and stinging sensations from under their skin. ${ }^{19-21}$ Immune deficiency and the presence of inflammatory markers indicating cytokine release suggest
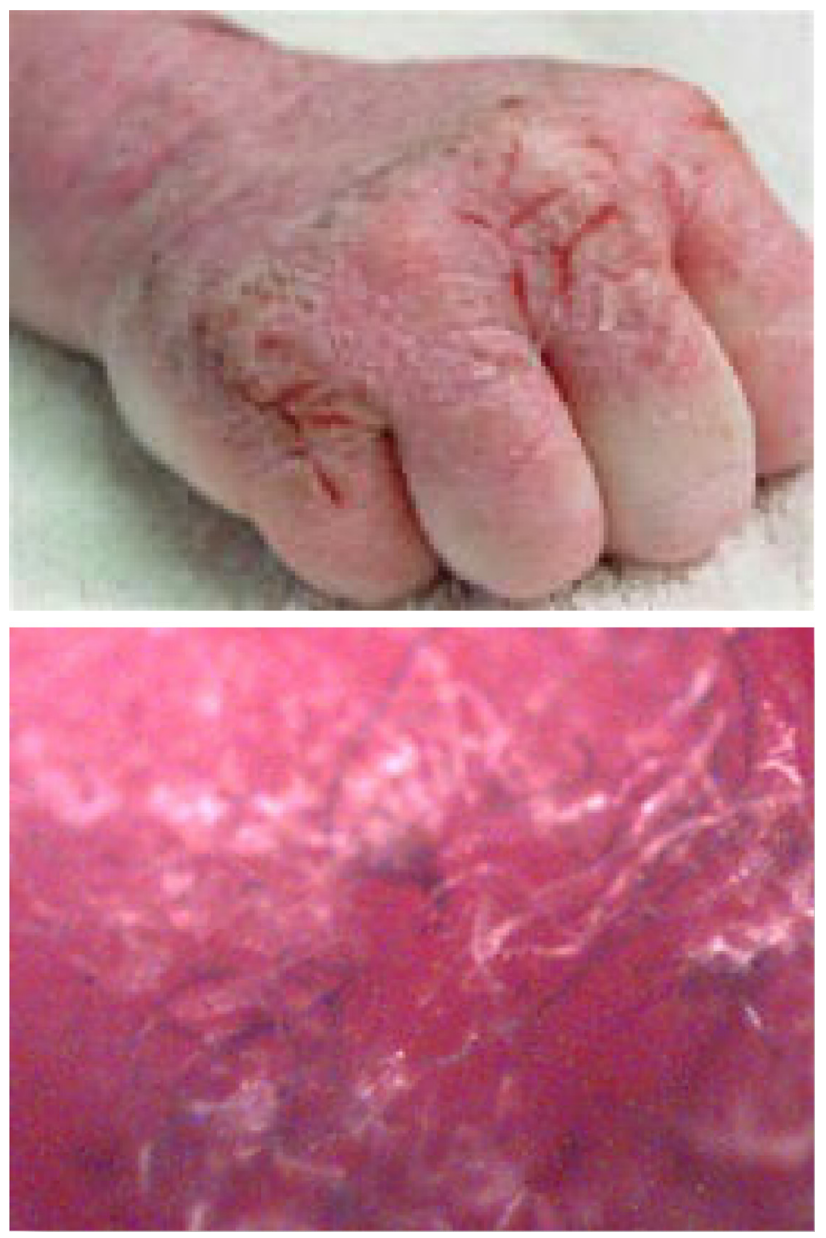

Figure 2 Morgellons disease. Note painful ulcerating lesions on hand (top) and subcutaneous white and blue fibers (bottom, 60× magnification).

Photographs courtesy of the Charles E Holman Foundation, reprinted with permission.

Note: Reproduced with permission from the website of the Charles E Holman Foundation (www.thecehf.org).

that an infectious process is involved, ${ }^{24}$ and Morgellons disease has been associated with spirochetal infection. ${ }^{25}$ These patients often have positive B. burgdorferi Western blots or Lyme-like symptoms, suggesting a high likelihood of Lyme borreliosis. ${ }^{20,25}$

A key difference between BDD and Morgellons disease is the veterinary community's response to BDD versus the medical community's response to Morgellons disease. While digital dermatitis has been the subject of extensive scientific investigation, unravelling the "mystery" of Morgellons disease has been hampered by claims that it results from delusions of parasitosis, ${ }^{26-28}$ and meaningful scientific studies have been carried out by only a handful of investigators. ${ }^{20,22,24,29,30}$ This report compares the clinical and laboratory features of the veterinary and human diseases. 
Table I Clinical features of digital dermatitis versus Morgellons disease

\begin{tabular}{|c|c|c|}
\hline Characteristic & Digital dermatitis & Morgellons disease \\
\hline History & Evolving disease, rapid spread & Evolving disease, rapid spread \\
\hline Environmental conditions & Moisture, rainy seasons, unsanitary & Contact with soil, unsanitary conditions, wet \\
\hline associated with prevalence & conditions & environments reported, third world travel also reported \\
\hline Gender and age distribution & $\begin{array}{l}\text { All breeds and genders, but mostly Holstein } \\
\text { and Friesian cows }\end{array}$ & $\begin{array}{l}\text { All genders, ages, and races, but mostly middle-aged } \\
\text { Caucasian women }\end{array}$ \\
\hline Geographic distribution & $\begin{array}{l}\text { Primarily northern hemisphere. US, Canada, } \\
\text { Europe, and Australia reported. In US, high } \\
\text { incidence in California }\end{array}$ & $\begin{array}{l}\text { Primarily northern hemisphere. US, Canada, Europe, } \\
\text { and Australia reported. In US, high incidence in California, } \\
\text { Texas, and Florida }\end{array}$ \\
\hline Etiology & $\begin{array}{l}\text { Multifactorial. Spirochetes and other bacteria } \\
\text { are present in lesions and required for successful } \\
\text { experimental infection. Moist unsanitary } \\
\text { environmental conditions and female gender } \\
\text { are predisposing factors }\end{array}$ & $\begin{array}{l}\text { Unknown etiology, but evidence suggests multifactorial } \\
\text { etiology. Reactivity to Borrelia burgdoferi, clinical Lyme } \\
\text { diagnosis, and Lyme-like symptoms suggests spirochetal } \\
\text { involvement. Serological evidence of coinfecting } \\
\text { tick-borne microorganisms suggests coinvolvement with } \\
\text { other pathogens vectored by ticks. Unsanitary environmental } \\
\text { conditions and female gender may be predisposing factors }\end{array}$ \\
\hline Contagiousness & Considered to be highly contagious & Familial associations suggests contagiousness \\
\hline Symptoms & $\begin{array}{l}\text { Lameness, weight loss, loss of condition, } \\
\text { decreased milk production in dairy cattle }\end{array}$ & $\begin{array}{l}\text { Lyme-like symptoms including joint pain, cognitive } \\
\text { dysfunction, neuropathy, fatigue, and rapid pulse }\end{array}$ \\
\hline $\begin{array}{l}\text { Response to antibiotic } \\
\text { therapy }\end{array}$ & $\begin{array}{l}\text { Yes, primarily treated by local antibiotic sprays } \\
\text { and disinfecting foot washes }\end{array}$ & Yes, responds to antibiotics \\
\hline
\end{tabular}

\section{Morgellons disease History}

Morgellons disease is a name given to an emerging, unusual dermopathy by Mary Leitao, a housewife who had previously worked as a laboratory technician. In 2001, her two-year old son suffered from lesions that, upon microscopic examination, revealed red, blue, white, and black fibers. The name came from a monograph entitled "A Letter to a Friend" by Sir Thomas Brown in 1690 describing an illness characterized by "outbreaks of harsh hairs" on the backs of children in

Table 2 Laboratory features of digital dermatitis versus Morgellons disease

\begin{tabular}{lll}
\hline Characteristic & Digital dermatitis & Morgellons disease \\
\hline $\begin{array}{l}\text { Detection of spirochetes } \\
\text { in lesions }\end{array}$ & Treponema spp & None detected \\
$\begin{array}{ll}\text { Detection of coinfecting } \\
\text { pathogens in lesions }\end{array}$ & Yes, many bacterial species & Polymerase chain reaction testing revealed no significant \\
$\begin{array}{l}\text { Presence of fibers or } \\
\text { filaments }\end{array}$ & Keratin filaments/fibers reaching several & difference compared with controls \\
Positive serology & centimeters described & Fibers/filaments up to several centimeters long and of \\
to Borrelia burgdorferi & Positive serology reported, Treponema spp. shown & unknown composition described \\
Positive serology for & to cross react with Borrelia burgdorferi antigens & Positive serology frequently reported (clinical Lyme \\
\hline
\end{tabular}

coinfecting pathogens

Histology of lesions

Changes to keratinized

tissue other than skin

Fiber/filament

composition

Color of fibers

Lesion location

Gross appearance

of lesions
Said to resemble those of yaws, hyperplasia, acanthosis, and elongated keratinocytes observed that may be involved with filament production

Hair loss in lesion, hypertrophic hair growth surrounding lesion, heel deformities, clubbed hooves, undercutting of hoof wall reported Keratin

Mostly white, gray or off-white

Mostly heel bulbs on skin above the coronet band Early lesions are concave, painful; late, chronic lesions are convex, granulomatous with protruding filaments; healing lesions are hyperpigmented, dark gray rubbery scars
Not well described, may bear a resemblance to yaws, hyperplasia reported. Fibers observed under and in skin, and piercing through skin. Fibers have been reported growing out of hair follicles

Patients have reported changes to texture and feel of hair, ${ }^{25}$ deformity and loss of toe/fingernails reported ${ }^{49}$

Unknown, but cellulose proposed, possibly keratin (physical and histological properties consistent) White, red, blue, purple, black (all possible colors seen in keratin)

Lesions anywhere, may indicate disseminated infection Concave, painful; fibers may protrude from skin lesion; may scab; healing tissue hyperpigmented 
Languedoc, France. In 2004, after apathy and dismissal by numerous doctors (including Dr Fred Heldrich from Johns Hopkins University, who suggested that Leitao might suffer from Munchausen by proxy syndrome), she founded the nonprofit Morgellons Research Foundation to raise awareness and funding for research into this disfiguring and disabling condition. $^{20,21,31-33}$

Many physicians continue to equate Morgellons disease with delusions of parasitosis. ${ }^{34-37}$ It is unknown when this disease first appeared, but descriptions of delusions of parasitosis date back to the 1950s and 1960s. Some of these early cases mention "threads" or other debris coming from skin and failure of psychotherapy, and thus may have been cases of Morgellons disease. ${ }^{38}$ The 2006 report by Savely et al of a patient who had Morgellons disease for 20 years provides evidence that the disease dates to the mid 1980s. ${ }^{20}$

Morgellons disease has been debated publicly through extensive media coverage, including television segments on major networks, and it was the cover story of the Washington Post magazine on January 26, 2008. ${ }^{39-43}$ The disease was also featured in the popular science magazine "New Scientist". ${ }^{27}$ This media coverage has led some physicians to blame the Internet for spreading beliefs of parasitosis and causing the increase in self-diagnosed Morgellons disease sufferers. ${ }^{44-46}$ Studies attempting to elucidate the disease process and its etiology appear to be hampered by the ongoing heated debate.

In 2006, pressure from the Morgellons Research Foundation prompted the US Centers for Disease Control and Prevention (CDC) to announce that it had launched an investigation. In May 2007, Dan Rutz, a CDC communication specialist, was quoted as saying in a television interview, "There is nothing to imply there is an infectious process, but our mind is open to everything, including that remote possibility". ${ }^{26}$ After issuing a preliminary report in 2009, the CDC declared in 2011 that data analysis was complete and had been submitted for publication in a peer-reviewed journal. To date, the results have not been publicly disclosed..$^{25,47}$

\section{Clinical aspects}

Patients with Morgellons disease frequently describe crawling, stinging, insect-like sensations, or sensations of "something trying to penetrate the skin from the inside out". ${ }^{20,25}$ These sensations are accompanied by slow-healing skin lesions that appear spontaneously. Skin lesions can be minor to disfiguring and associated with fibrous material either in strands or balls of wound-up fibers. ${ }^{20,25}$ Granules have been observed that may demonstrate attached fibers.
"Black specks" or "black oil" associated with lesions have been reported. Fibers may be present under unbroken skin as well as in lesions and scabs. ${ }^{20,25}$ Microangiomas found upon examination are reported. ${ }^{24}$ Healed lesions demonstrate hyperpigmented scar tissue. ${ }^{25}$ Patients report changes to their hair ${ }^{48}$ and changes to finger and toenails. ${ }^{49}$ The nail changes in Morgellons disease resemble those associated with syphilis. In that condition, the nail wall becomes raised, with inflammation and suppuration of tissue surrounding the nail resulting in nail plate destruction, separation of the nail, and defective growth at the nail matrix. ${ }^{50}$ Nail changes in Morgellons disease provide further evidence of spirochetal involvement, as noted above.

Patients with Morgellons disease experience symptoms consistent with systemic pathology, including fatigue, cognitive disability (described as "brain fog"), fibromyalgia, joint pain, vision decline, neurological disorders, hair loss, disintegration of teeth, intermittent fever, low body temperature, and sleep disturbances. ${ }^{20,24,48}$ Frequent physical findings include reduced exercise capacity, peripheral neuropathy, delayed capillary refill, abnormal Romberg's sign, decreased body temperature, cardiac arrhythmias, and tachycardia. ${ }^{23}$ Many patients with Morgellons disease report inability or impaired ability to work. Most patients have been diagnosed with psychiatric or psychosomatic illness, and report that physicians are dismissive and attribute lesions to delusional parasitosis and self-mutilation..$^{20,24,48}$ While some patients with Morgellons disease do demonstrate behavioral aberrancies including a delusional component, many do not, and psychiatric manifestations are possibly from an underlying pathogenic process. ${ }^{22}$ Symptoms in some patients such as headaches, visual abnormalities, short-term memory loss, and emotional lability are consistent with central nervous system involvement. ${ }^{24}$

Patients with Morgellons disease regularly demonstrate abnormal laboratory findings, including occasional low-grade anemia, test results indicating endocrine dysfunction such as diabetes and thyroid dysfunction, test results indicative of immune dysfunction such as low CD57+ natural killer cells and inflammatory markers, such as elevated C-reactive protein, complement $\mathrm{C} 4 \mathrm{a}$, tumor necrosis factor-alpha, interferon-gamma, and interleukin- 6 . $^{23,25}$

\section{Distribution and predisposing factors}

According to the Morgellons Research Foundation, there are over 15,000 self-identified sufferers from 15 countries including the US (all 50 states), Canada, the UK, Australia, South Africa, and the Netherlands. In the US, most cases are 
reported from California, followed by Texas and Florida. ${ }^{25,48}$ The prevalence of Morgellons disease in southern coastal areas of the US suggests that the incidence is greater in moist humid climates. The disease appears to be more prevalent in the northern hemisphere. ${ }^{48}$ Some family members of patients with Morgellons disease experience the above symptoms with or without associated dermal lesions, and have also reported similar symptoms in family pets. ${ }^{20,24}$ This implies that the disease may be infectious in nature and transmitted from person to person or transmitted from an inciting agent during familial environmental exposure. Contact with soil or unsanitary environmental conditions appears to be a contributing factor. ${ }^{20,24}$ Onset has been associated with rural residence or recent rural travel. ${ }^{24}$ Although findings by the Morgellons Research Foundation indicate that Morgellons disease affects equal numbers of males and females, other studies have indicated that this disease is more prevalent among middle-aged Caucasian women. ${ }^{25}$

\section{Pathophysiology}

Skin biopsies typically reveal nonspecific pathology or inflammatory processes with no observable pathogens, ${ }^{20}$ although hyperplasia has been reported, ${ }^{49}$ and histology may therefore resemble that of yaws lesions. ${ }^{6}$ A forensic scientist from the Tulsa Police Crime Laboratory in Oklahoma, US, could not find a match with known fibers in the national data base for the Federal Bureau of Investigation. ${ }^{26}$ Spectroscopic analysis could not match the fibers with any of 880 compounds commonly used in manufactured commercial fibers, and dye-extracting solvents failed to release coloration. ${ }^{27}$ The fibers have been shown to be very strong and heat-resistant, so much so that attempts to analyze contents by gas chromatography were not possible..$^{27,30}$ Microscopy of fibers reveals a white, blue, red, purple or black coloring and a "metallic-looking" sheen. They may also appear to be coated with minerals, and do not demonstrate a cellular structure. ${ }^{29,30}$ Fibers associated with skin have been shown to emerge or stab through skin and skin lesions, and some appear to have grown from hair follicles..$^{29,30}$ These fibers also fluoresce under ultraviolet light. ${ }^{30}$

There is a suggestion that the fibers may contain cellulose. ${ }^{20}$ A cellulose-protein complex was identified as a minor constituent of mammalian connective tissue, with increased amounts of such material noted in tissues from scleroderma patients and patients with other pathological skin conditions. ${ }^{51}$ The cellulose-producing plant pathogen Agrobacterium has been shown to infect nonplant species including humans, and polymerase chain reaction screening of tissue samples from five patients with Morgellons disease indicates the presence of Agrobacterium genes, implying a possible etiological involvement. ${ }^{29,52}$ However, further polymerase chain reaction testing has yet to reveal a link between tissue samples and pathogens, showing no significant statistical difference between negative controls and patients with Morgellons disease. ${ }^{30}$

There is a connection between Morgellons disease and Lyme disease, because the majority of patients with Morgellons disease demonstrate serological reactivity with $B$. burgdorferi proteins in Western blots ${ }^{20,25}$ or have a high probability of a Lyme disease diagnosis based on meeting defined criteria for the diagnosis. ${ }^{25}$ In addition, Morgellons disease is associated with positive serological evidence of coinfecting tick-borne pathogens, such as Babesia spp, Anaplasma phagocytophilum, Ehrlichia chaffeensis, and Bartonella henselae. ${ }^{25}$ Further evidence of a bacterial etiology is the fact that patients with Morgellons disease respond to antibiotic therapy. ${ }^{20,23}$

\section{Bovine digital dermatitis History}

Evidence that spirochetes are associated with livestock lameness was first described by Breveridge in 1936 when he isolated spirochetes from sheep footrot in Australia. ${ }^{53}$ In 1966, an outbreak of foot infection associated with spirochetes in Australian dairy cattle was described by Egerton and Parsonson. ${ }^{54}$ However, BDD was first reported as an emerging disease in the early 1970s when an outbreak of ulcerative proliferative lesions was reported in Italy. ${ }^{1}$ The disease has since spread throughout Europe and the UK. ${ }^{9,55-57}$ It was first identified in the US in New York State in 1974 and has since spread throughout the US and Canada. ${ }^{2,17}$ The incidence and prevalence continue to rise rapidly. ${ }^{15,16}$ In a 1998 incidence study in the US, BDD was reported in $43 \%$ of US dairy herds. Of infected herds, $78 \%$ had reported that the infection first occurred in 1993 or later. ${ }^{2}$ It is hypothesized that spirochetes occurring naturally in the farming environment without causing significant pathology for many decades suddenly appeared as an emerging disease entity through some triggering event or process, causing a pathogenic upshift in the Treponema spp associated with BDD. ${ }^{15,16}$

\section{Clinical aspects}

BDD is a major cause of lameness in dairy cattle and causes decreased milk production, loss of body condition, and weight loss. ${ }^{1,3}$ The pathology of the disease may be 
mild, with no obvious lameness, moderate, with afflicted cattle walking on their toes, or incapacitating. ${ }^{58}$ Atrophy of heel bulbs and clubbed hooves may result from infection. ${ }^{58}$ Sheep with digital dermatitis may suffer undercutting of the hoof wall and complete shedding of the hoof. ${ }^{59} \mathrm{BDD}$ is described as superficial digital dermatitis at the coronary margin $^{3}$. It is most often seen on the posterior border of the interdigital space midway between the heel bulbs. ${ }^{60,61}$ Most lesions appear on the hind feet ${ }^{62}$ but may affect all four feet. ${ }^{58}$ The diagnostic criteria of BDD are parakeratotic hyperkeratosis, epidermal acanthotic hyperplasia, ulcerated dermal papillae tips, and invasion of the stratum spinosum and dermal papillae by spirochetes identified as Treponema spp. ${ }^{63}$ Lesions are said to bear a resemblance to those of yaws, ${ }^{58}$ and cattle with BDD are serologically reactive to $B$. burgdoferi antigens, ${ }^{7,8}$ suggesting a spirochetal association.

Early erosive lesions are characterized by wet eczema with matting of superficial hairs, hyperemia, and swelling that develops into erosive dermatitis. At this stage, the surface level is flat or lower than the epithelial level (concave). Lesions are painful and bleed easily. ${ }^{64,65}$ As the disease progresses, granulomatous lesions develop, marked by ingrowth of keratin pins on the erosion surface and progressive keratinization. Lesions may rise above the epithelial level as their diameter increases and are less prone to bleeding. ${ }^{13}$ In late chronic infection, proliferative lesions are characterized by pronounced rete ridge formation with broad-based tips at the dermoepidermal border, hyperplasic stratum corneum, acanthotic stratum spinosum, scarce keratohyaline granules, and horny columns in hemorrhagic cell detritus, with empty vacuoles in the stratum granulosum, neutrophils in the epidermis, and plasma cells in the dermis. ${ }^{13}$ Projections consisting of elongated, ballooned, necrotic, or keratinized keratinocytes can be seen, ${ }^{17}$ with proliferation of keratin filaments reaching up to several centimeters in length. ${ }^{18}$

Diagnosis of BDD remains clinical, because serological tests lack sensitivity and specificity. ${ }^{17,18}$ After treatment, lesions may regress and form dark, rubbery, firm scabs that eventually fall off. Healing can vary depending on the severity of the lesion prior to treatment. Skin may be smooth, have remnant scar tissue, or may remain hyperkeratotic. Reactivation may occur if regression is incomplete. ${ }^{4}$ Treatment includes cleaning, antibiotic sprays, and antibiotic and formalin foot baths. ${ }^{18}$ Parenteral antibiotics are of limited effectiveness, costly, and involve milk-withdraw time, so are seldom used..$^{9,17,18}$

\section{Etiology and pathophysiology}

The etiology of BDD is thought to be multifactorial, involving spirochetal infection, coinfection with other bacteria, and environmental conditions that favor the establishment of infection. Treponeme spirochetes are associated with BDD and have been repeatedly characterized and isolated from BDD lesions, ${ }^{9,11-16,65-67}$ and involvement with multiple treponeme species has been reported, including some species that are phylogenetically related to human isolates. ${ }^{15-17,68}$ Spirochetes within necrotic and outer proliferating epidermal cells appear to be invasive. Healthy tissue is not associated with spirochetes, and other bacteria are limited to necrotic layers. ${ }^{13,17}$ This suggests a primarily spirochetal infection, and the significance of coinfection with other bacteria is debated..$^{15-17}$

Bacteria that have been isolated from BDD lesions and may be cofactors in establishing infection include Bacteroides spp,${ }^{9,69}$ Campylobacter spp, ${ }^{13,61}$ Dichelobacter nodosus, ${ }^{11}$ Fusobacterium necrophorum, Fusobacterium nucleatum, Porphyromonas levii, and Prevotella spp..$^{70,71}$ Early attempts at experimental infection with injected tissue homogenates failed. ${ }^{17,60,72}$ Subsequently successful experimental infection using a BDD tissue homogenate was achieved in calves. Continual wetting and wrapping of the epidermis created a hydropic and relatively anaerobic environment favorable for establishing treponeme infection. ${ }^{58}$ Experimental induction of BDD lesions was recently achieved using pure cultured treponemes free of other bacteria, an observation that supports a primary role for spirochetes in this disease. ${ }^{73}$

Treponeme phylotypes involved with BDD are more closely related to human oral and genital treponemes than to those identified in the bovine gastrointestinal tract. Spirochetes that resemble Treponema phagedenis are most commonly associated with BDD globally and are most similar to the human genital strain T. phagedenis. Studies involving phylogenetic clustering of BDD spirochetes have revealed other strains related to Treponema denticola, Treponema vincentii, Treponema putidum, Treponema medium, and Treponema pedis. ${ }^{74-79}$

\section{Distribution and predisposing factors}

All ages and breeds are susceptible to BDD. ${ }^{80}$ Holstein and Friesian cows are the most susceptible, especially lactating heifers and three-year-old cows..$^{5,55,56,80,81}$ This suggests that hormones may play a role in susceptibility to infection. ${ }^{5}$ Although many beef cattle end up in feedlots that are unsanitary, which would be expected to provide favorable conditions for infection, these animals are rarely affected. ${ }^{82}$ 
Infection is associated with wet environments, muddy corrals, and poor animal husbandry. In Californian herds, an increased rate of infection is seen in late spring to early summer, 1-3 months after the start of the rainy season when most affected cows have been standing in manure-rich slurry. ${ }^{5}$ After a farm has become infected, BDD cannot be eradicated and recurring infection is likely, especially in newly introduced heifers. ${ }^{83}$ Spirochetes have been detected by polymerase chain reaction in all stages of healing and they are not completely eradicated by treatment. ${ }^{84}$ It is hypothesized that environmental conditions related to poor hygiene (contact with wet slurry and fecal ammonium and microtrauma) favor spirochetal infection and an increased incidence of disease. ${ }^{15,16}$

\section{Discussion}

The fact that unusual fiber or filament production is associated with spirochetal infection in BDD might suggest that a similar process is involved in Morgellons disease. Patients with Morgellons disease have evidence of spirochetal infection demonstrated by serological reactivity to $B$. burgdorferi antigens, clinical Lyme diagnosis, and symptoms consistent with Lyme disease. Both BDD and Morgellons disease appear to have a multifactorial etiology involving spirochetes and coinfecting pathogens. They are both emerging, rapidly spreading diseases. Both BDD and Morgellons disease are predominantly found in females, and a female predominance in patients with persistent Lyme symptoms has likewise been demonstrated. ${ }^{25}$

$\mathrm{BDD}$ is recognized by veterinarians to be an important cause of morbidity in dairy cattle, causing a significant financial loss for the dairy industry and justifying the degree of research attention it has received. In the case of Morgellons disease, mainstream medicine has written off people with unexplained dermopathy as delusional. Media and the Internet are said to be factors contributing to its increasing incidence and geographical spread. The Internet through its ability to instantly disperse information, reliable or not, is blamed for misinforming patients and causing support of disease beliefs that are said to lack scientific evidence. ${ }^{44}{ }^{46}$ The lack of a universally accepted clinical definition for Morgellons disease has resulted in patients with various diseases, some psychiatric and others not, being categorized together in many studies. ${ }^{85}$ On the other hand, the few researchers who have examined patients exhibiting dermopathy with fibers that are subcutaneous or imbedded in lesions have provided convincing evidence that the disease is not self-inflicted and that a pathogen may be involved. ${ }^{20,25}$ Some patients with itchy dermopathy can be expected to scratch lesions, but that does not mean that an underlying pathology does not exist.
Both BDD and Morgellons disease demonstrate unusual dermal filaments or fibers, and both appear to be associated with spirochetal infection. In the case of BDD, spirochetal infection is the primary etiological agent for the disease, but other factors and coinfection with other pathogens are required before pathology can occur. In human periodontal disease, spirochetal infection is preceded by infection with proteolytic Gram negative bacteria, and the resulting inflammation creates anaerobic conditions favorable for spirochetal invasion. ${ }^{74-76}$ This also appears to be the case in BDD. Large numbers of environmental organisms, anaerobic conditions, and microtrauma allow treponemes to penetrate into deep epithelial strata. ${ }^{15,16}$ The link between Morgellons disease and onset associated with unsanitary or dirty conditions and increased incidence in wet geographical areas suggests that environmental organisms from that type of habitat may play a role in Morgellons disease..$^{20,25}$ B. burgdorferi infection has been linked to Morgellons disease, and spirochetes have been linked to fiber formation in BDD. Therefore, it is reasonable to hypothesize that spirochetes are involved with fiber formation in Morgellons disease.

In BDD, keratinocytes have been shown to activate cytokine production and influence inflammatory markers. ${ }^{8}$ Morgellons patients also demonstrate inflammatory markers that indicate cytokine release. ${ }^{23,24}$

In chronic BDD infection, there is evidence that spirochetes damage keratinocytes, resulting in the formation of unusual keratin fibers. ${ }^{15,16}$ Spirochetes have been shown to activate cytokines and other inflammatory markers. ${ }^{86}$ Keratinocytes influence inflammatory cell movement and retention in the epidermis via cytokine release. ${ }^{87,88}$ Tissue damage is aggravated by neutrophil infiltration, inflammatory mediators, and cytokines. ${ }^{15,16}$ Epidermal proliferation, hyperplasia, and influx of neutrophils, monocytes, and lymphocytes result in damage to keratinocytes and production of abnormal keratin filaments. The production of keratinolytic toxins by treponemes has been proposed $^{8}$ and B. burgdorferi has been shown to stimulate inflammatory chemokine secretion. ${ }^{89,90}$ Of note, treponemes cannot be detected in tissue from tertiary syphilis lesions, even though it is an undisputed fact that infection with treponemes is the cause of the dermopathy. Damage to keratinized tissues, hair, toenails, fingernails, and skin has been demonstrated in tertiary syphilis in the absence of detectable spirochetes..$^{50,91-94}$

There is strong evidence that Morgellons is not a delusional disease. ${ }^{20,25}$ Fibers are found under unbroken skin, indicating that they are not self-inflicted. Because they are not self-implanted textile fibers, they must be produced within the skin. The lack of detectible pathogens in lesions suggests also that fibers are human cell products..$^{20,25}$ Keratinocytes 
are the cells most likely to produce these fibers. They are the predominant cells found in skin, and they are found in hair follicles. Fibers have been found embedded in and piercing skin, and they have been observed growing out of hair follicles. Recently we examined patterns of fiber formation in patients with Morgellons disease, and we found that these fibers possess physical and microscopic characteristics of keratin, often with elaborate shapes and reflected colors (Figure 3). The results of our investigation will be described in a forthcoming paper.
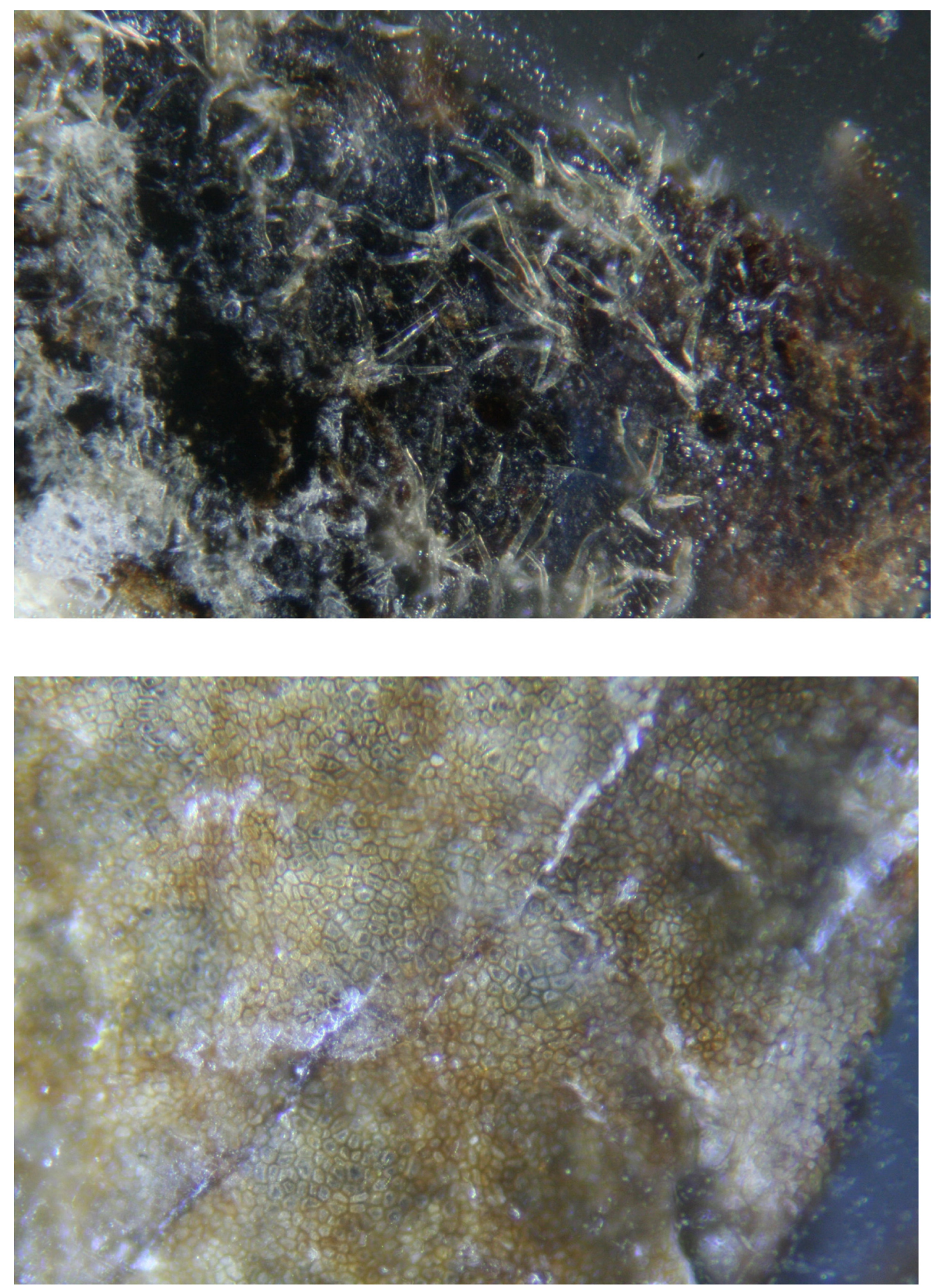

Figure 3 Morgellons fibers at 100x magnification. Note floral-shaped fibers on external surface (top) and pavement epithelium on internal surface (bottom) of epidermal section. 
In view of the above discussion, there is evolving evidence that Morgellons fibers have physical properties consistent with keratin. Keratin and chitin are the strongest known biofibers, and keratin shows no cellular structure. Likewise Morgellons fibers are very strong and show no cellular structure, consistent with keratin filaments. They are colored blue, red, purple, and black, which are all colors found naturally in keratin. Solvents have not been able to extract pigments. Keratin can demonstrate different colors including blue, red, and purple, not from pigment production but from microscopic refractive structures that produce constructive interference of light diffracting from structural layers. ${ }^{95}$ Bacteria have been shown to influence and enhance color intensity in keratin. ${ }^{96}$ The fibers demonstrate a "metallic-looking" sheen, consistent with keratin and iridescent coloring. Morgellons fibers fluoresce under ultraviolet light, a property that has been observed to occur with keratin fibers. ${ }^{97,98}$ Thus keratin composition may explain the "mysterious" fibers in Morgellons disease. The etiopathogenesis of these fibers remains to be determined.

\section{Conclusion}

BDD and Morgellons disease demonstrate complex multifactorial etiologies. In the case of BDD, the etiology is primarily spirochetal with coinvolvement of other bacteria, while in patients with Morgellons disease, clinical Lyme diagnosis and serological detection of $B$. burgdorferi points to spirochetal infection, and laboratory evidence suggests coinfection with other tick-borne pathogens. Microscopic studies and physical evidence suggest that Morgellons disease might have a similar pathology to BDD.

Proliferative BDD lesions demonstrate keratinocytes producing abnormal keratin fibers that may reach several centimeters in length. Morgellons disease likewise demonstrates unusual fiber formation in skin and hair follicles where keratinocytes are the predominant cells. Evidence indicates that keratinocytes are the most likely source of the "mysterious" Morgellons fibers, and that these fibers are likely composed of keratin. Keratin is consistent with the microscopic, chemical, and physical properties demonstrated by Morgellons fibers. The lack of obvious spirochetal infection in Morgellons lesions does not preclude their involvement in the disease process; spirochetes are not easily detectable in secondary syphilis lesions and are rarely if ever detected in tertiary syphilis lesions. Spirochetes do not have to be identifiable in lesions to cause dermopathy.

BDD and Morgellons disease are evolving pathologies that share a remarkable number of similarities (Tables 1 and 2).
While scientific research has elucidated many clinical and laboratory features of BDD, much of the mystery surrounding Morgellons disease has yet to be resolved. The belief held by mainstream medicine that Morgellons disease is a delusional psychiatric illness deters scientific investigation concerning this phenomenon. Morgellons disease does not appear to be a delusional disease, as demonstrated by fibers occurring under unbroken skin, and patients with Morgellons disease have clinical and laboratory evidence indicating an infectious inflammatory disease process similar to BDD. Comparison between these emerging pathologies may reveal the secrets behind the human dermopathy.

\section{Acknowledgments}

The authors thank Gordon Atkins, Robert Bransfield, Dorte Dopfer, Doug Kahn, Alan MacDonald, Peter Mayne, Deryck Read, Janet Sperling, Michael Sweeney, and Randy Wymore for their helpful discussions. We are grateful to Harriet Bishop and Cindy Casey for providing first-hand information about Morgellons disease, and Lorraine Johnson for manuscript review.

\section{Disclosures}

RBS serves without monetary compensation on the medical advisory panel for QMedRx Inc. He has no financial ties to the company. MJM has no conflicts of interest to report.

\section{References}

1. Cheli R, Mortellaro CM. Digital dermatitis in cattle. Proc 8th Int Meet Dis Cattle; Milan, Italy. 1974;8:208-213.

2. Weaver AD, Andersson L, De Laistre Banting A, et al. Review of disorders of the ruminant digit with proposals for anatomical and pathological terminology and recording. Vet Rec. 1981;108(6):117-120.

3. Dopfer D, Willemann MA. Standardisation of Infectious Claw Diseases. Proceedings of the 10th International Symposium on Lameness in Ruminants; 1998; Lucerne, Switzerland; 1998:244-254.

4. Wells SJ, Garber LP, Wagner BA. Papilomatous digital dermatitis and associated risk factors in US dairy herds. Prev Vet Med. 1999;38(1):11-24.

5. Read DH, Walker RL. Papilomatous digital dermatitis (footwarts) in California dairy cattle: clinical and gross pathologic findings. $J$ Vet Diagn Invest. 1998;10(1):67-76.

6. Engelkens HJ, Vuzevski VD, Judanarso J, et al. Early yaws: a light microscopic study. Genitourin Med. 1990;66(4):264-266.

7. Egerton JR. Foot-rot of cattle, goats and deer. In: Egerton JR, Yong WK, Riffkin GG, editors. Foot-Rot and Abscesses of Ruminants. Boca Raton, FL: CRC Press Inc; 1988:47-56.

8. Blowey RW, Done SH, Cooley W. Observations on the pathogenesis of digital dermatitis in cattle. Vet Rec. 1994;135(5):115-117.

9. Blowey RW, Sharp MW. Digital dermatitis in dairy cattle. Vet Rec 1988;122(21):505-508.

10. Read DH, Walker RL, Castro AE, Sundberg JP, Thurmond MC. An invasive spirochaete associated with interdigital papillomatosis of dairy cattle. Vet Rec. 1992;130(3):59-60. 
11. Scavia G, Sironi G, Mortellaro CM, Romusi S. Digital dermatitis: further contribution on clinical and pathological aspects in some herds in northern Italy. Proc Int Symp Dis Ruminant Digit. 1994;8:174-176.

12. Grund S, Nattermann H, Horsch F. Electron microscopic detection of spirochetes in dermatitis digitalis of cattle. Zentralbl Veterinarmed $B$. 1995;42(9):533-542.

13. Dopfer D, Koopmans A, Meijer FA, et al. Histological and bacteriological evaluation of digital dermatitis in cattle, with special reference to spirochaetes and Campylobacter faecalis. Vet Rec. 1997;140(24): 620-623.

14. Demirkan I, Carter SD, Murray RD, Blowey RW, Woodward MJ. The frequent detection of a treponeme in bovine digital dermatitis by immunochemistry and polymerase chain reaction. Vet Microbiol. 1998;60(2-4):285-292.

15. Vink WD, Jones G, Johnson WO, et al. Diagnostic assessment without cut-offs: application of serology for the modelling of bovine digital dermatitis infection. Prev Vet Med. 2009;92(3):235-248.

16. Evans NJ, Brown JM, Demirkan I, et al. Association of unique, isolated treponemes with bovine digital dermatitis lesions. J Clin Microbiol. 2009;47(3):689-696.

17. Borgmann JE, Bailey J, Clark EG. Spirochete-associated bovine digital dermatitis. Can Vet J. 1996;37(1):35-37.

18. Ames NK. Healing hairy heel warts. Michigan Dairy Review. 1997; 2:14.

19. Savely VR, Leitao MM. Skin lesions and crawling sensations: disease or delusion? Adv Nurse Pract. 2005;13(5):16-17.

20. Savely VR, Leitao MM, Stricker RB. The mystery of Morgellons disease: infection or delusion? Am J Clin Dermatol. 2006;7(1):1-5.

21. Savely VR, Stricker, RB. Morgellons disease: the mystery unfolds. Expert Rev Dermatol. 2007;2:585-591.

22. Bransfield RC. Morgellons disease. Psychiatric News. 2007;42:24.

23. Harvey WT. Morgellons disease. J Am Acad Dermatol. 2007;56: 705-706.

24. Harvey WT, Bransfield RC, Mercer DE, Wright AJ, Ricchi RM, Leitao MM. Morgellons disease, illuminating an undefined illness: a case series. J Med Case Reports. 2009;3:8243.

25. Savely VR, Stricker RB. Morgellons disease: analysis of a population with clinically confirmed microscopic subcutaneous fibers of unknown etiology. Clin Cosmet Investig Dermatol. 2010;3:67-78.

26. Wikipedia. Available from: http://en.wikipedia.org/wiki/Morgellons. Accessed October 4, 2011.

27. Eklan D. Morgellons disease: the itch that won't be scratched. New Scientist. 2007;2621:46-49.

28. Monaghan E. All in the head? London Times: On line (UK). 2006. Available from: http://timesonline.co.uk/tol/comment/article721795. ece. Accessed October 4, 2011.

29. Citovsky V. Research update. Morgellons Research Foundation. 2007. Available from: http://www.morgellons.org/suny.htm. Accessed October 4, 2011.

30. Wymore RS. Morgellons disease research; shotgun DNA analysis, PCR, microscopy and spectroscopy. Morgellons Medical Conference; 2011; Austin, Texas. Available from: www.thecehf.org/resources/abstracts2011.pdf. Accessed October 4, 2011.

31. Hyde J. The plague, bizzare fibers, black sweat, bugs under the skin, welcome to the controversial world of Morgellons disease. Dallas Observer. 2006. http://www.dallasobserver.com/2006-2007-20/news/ the-plague/full. Accessed October 4, 2011.

32. Harlan C. Mom fights for answers on what's wrong with her son. Pittsburgh Post-Gazette. 2006. Available from: http://www.post-gazette. com/pg/06204/707970-07985.stm. Accessed October 4, 2011.

33. DeVita-Raeburn F. Delusional parasitosis facilitated by web-based dissemination. Am J Psychiatry. 2008;165(12):1612.

34. Freudenmann RW, Lepping P. Delusional infestation. Clin Microbiol Rev. 2009;22(4):690-732.

35. Freudenmann RW, Kolle M, Schonfeld-Lecuona C, Dieckmann S, Harth W, Lepping P. Delusional parasitosis and the matchbox sign revisited: the international perspective. Acta Derm Venereol. 2010;90(5):517-519.
36. Harth W, Hermes B, Freudenmann RW. Morgellons in dermatology. J Dtsch Dermatol Ges. 2010;8(4):234-242.

37. Reid EE, Lio PA. Successful treatment of Morgellons disease with pimozide therapy. Arch Dermatol. 2010;146(10):1191-1193.

38. Tullet GL. Delusions of parasitosis. Br J Dermatol. 1965;77(8): 448-455.

39. McDade MB. Mysterious disease plagues more southlanders. CBS Broadcasting Inc. 2006. Available from: http://cbs2.com/ video/?id=18983@kcbs.dayport.com. Accessed October 4, 2011.

40. McFadden C. Mysterious skin disease causes itching, loose fibers. ABC News. 2006. Available from: http://abcnews.go.com/GMA/OnCall/ story? $\mathrm{id}=2246987 \&$ page $=1$. Accessed October 4, 2011.

41. Schulte B. Figments of the imagination? The Washington Post Magazine. 2008. Available from: http://www.washingtonpost.com/ wp-dyn/content/article/2008/01/16/AR2008011603134.html. Accessed October 4, 2011.

42. Harding A. Skin Infestation a delusion, study says. CNN.com. 2011. Available from: http://www.cnn.com/2011/HEALTH/05/16/skin. infestation.delusion/. Accessed October 4, 2011.

43. Harper J. CDC enlists military to study skin ailment. The Washington Times. 2008. Available from: http://www.washingtontimes.com/ news/2008/jan/18/cdc-enlists-military-to-study-skin-ailment/. Access October 4, 2011.

44. Koblenzer CS. The challenge of Morgellons disease. J Am Acad Dermatol. 2006;55(5):920-922.

45. Vila-Rodriguez F, MacEwan BG. Delusional parasitosis facilitated by web-based dissemination. Am J Psychiatry. 2008;165(12):1612.

46. Waddel AG, Burke WA. Morgellons disease? J Am Acad Dermatol. 2006;55(5):914-915.

47. Centers for Disease Control and Prevention (CDC). Unexplained dermopathy (also called "Morgellons"). Available from: http://www.cdc. gov/unexplaineddermopathy. Accessed July 8, 2011.

48. Morgellons Research Foundation (MRF). Available from: http://www. morgellons.org/. Accessed July 8, 2011

49. Casey C. Charles E. Holman Foundation. Available from: http://www. thecehf.org/. Accessed October 4, 2011.

50. MacLeod JM. Syphilitic onychia. Proc R Soc Med. 1910;3(Dermatol Sect):59-60.

51. Hall DA, Happey F, Lloyd PJ, Saxl H. Oriented cellulose as a component of mammalian tissue. Proc R Soc Lond B Biol Sci. 1960;151: 496-516.

52. Stricker RB, Savely VR, Zaltsman A, Citovsky V. Contribution of Agrobacterium to Morgellons disease. J Invest Med. 2007;55:S123.

53. Beveridge WI. A study of Spirochaeta penortha isolated from foot-rot in sheep. Austral J Exp Biol Med Sci. 1936;14:307-318.

54. Egerton JR, Parsonson IM. Isolation of Fusiformis nodosus from cattle. Aust Vet J. 1966;42(11):425-429.

55. Brizzi A. Bovine digital dermatitis. Bovine Practitioner. 1993;27: 33-37.

56. Gourreau JM, Scott DW, Rousseau JF. La dermatite digitee des bovins. Le Point Vet. 1992;24:49-57.

57. Whittier WD. Footwarts. Dairy. June 12-13, 1988.

58. Read DH, Walker RL. Experimental transmission of papillomatous digital dermatitis (footwarts) in cattle. Proc Int Symp Lameness Ruminants. Lucerne, Switzerland; 1998:270.

59. Sayers G, Marques PX, Evans NJ, et al. Identification of spirochetes associated with contagious ovine digital dermatitis. J Clin Microbiol. 2009;47(4):1191-1201.

60. Rebhun WC, Payne RM, King JM, Wolfe M, Begg SN. Interdigital papillomatosis in dairy cattle. J Am Vet Med Assoc. 1980;177(5):437-440.

61. Cornelisse JL, Van Asten AJ, Peterse DJ, Toussaint-Raven E. Proceedings of the 4th International Symposium on Disorders of the Ruminant Digit; Societe Francaise de Buiattrie, Paris - aison Alfort, France; 1982.

62. Roztocil V, Ulman L, Rusek T, Berankova E. Incidence and control of digital dermatitis of cattle kept on large dairy cattle units with open successive herd grazing. Monatshefte fuer Veterinaermed. 1988;43:536-539. 
63. Read DH, Walker RL. Papilomatous digital dermatitis: pathologic findings. Proceedings of the 8th International Symposium on Disorders of the Rumin Digit; Banff, Canada; 1994:156-157.

64. Mortellaro CM, Cheli R, Toussaint-Raven E, Cornelisse JL. Digital dermatitis in cattle. Pro Veterinario. 1985;3:9-12.

65. Walker RL, Read DH, Loretz KL, Nordhausen RW. Spirochetes isolated from dairy cattle with papilomatous digital dermatitis and interdigital dermatitis. Vet Microbiol. 1995;47(3-4):343-355.

66. Demirkan I, Carter SD, Hart SD, Woodward MJ. Isolation and cultivation of a spirochaete from digital dermatitis. Vet Rec. 1999;145(17): 497-498.

67. Colligahan RJ, Naylor RD, Martin PK, Cooley BA, Buller N, Woodward MJ. A spirochete isolated from a case of virulent severe ovine foot disease is closely related to a Treponeme isolated from human periodontitis and bovine digital dermatitis. Vet Microbiol. 2000;74(3): 249-257.

68. Dewhirst FE, Tamer MA, Ericson RE, et al. The diversity of periodontal spirochetes by $16 \mathrm{~S}$ rRNA analysis. Oral Microbiol Immunol. 2000;15(3):196-202.

69. Yano T, Moe KK, Yamazaki K, Ooka T, Hayashi T, Misawa N. Identification of candidate pathogens of pappilomatous digital dermatitis in dairy cattle from quanititative $16 \mathrm{~S}$ rRNA clonal analysis. Vet Microbiol. 2010;143(2-4):352-362.

70. Koniarova I, Orsag A, Ledecky V. The role anaerobes in dermatitis digitalis et interdigitalis in cattle. Vet Med (Praha). 1993;38(10):589-596.

71. Moe KK, Yano T, Misumi K, et al. Detection of Fusobacterium necrophorum and Porphyromonas levii-like species in dairy cattle with papillomatous digital dermatitis. Microbiol Immunol. 2010;54(6) 338-346.

72. Basset HF, Monaghan ML, Lenham P, Doherty ML, Carter ME. Bovine digital dermatitis. Vet Rec. 1990;126:164-165.

73. Gomez A, Cook N, Dopfer D, Bernardoni N, Dusick A, Read D. An experimental infection model for digital dermatitis. Lameness in Ruminants Conference; Feb-Mar 2011; New Zealand. (Abstract A7.3).

74. Choi BK, Nattermann H, Grund S, Haider W, Gobel UB. Spirochetes from digital dermatitis lesions in cattle are closely related to treponemes associated with periodontitis. Int J Syst Bacteriol. 1997;47(1): 175-181.

75. Rijpkema SG, David GP, Hughes SL, Woodward MJ. Partial identitification of spirochaetes by polymerase chain reaction analysis of $16 \mathrm{~S}$ ribosomal RNA gene. Vet Rec. 1997;140(10):257-259.

76. Edwards AM, Dymock D, Woodward MJ, Jenkinson HE. Genetic relatedness and phenotypic characteristics of Treponema associated with human periodontal tissues and ruminant foot disease. Microbiology. 2003;149(Pt 5):1083-1093.

77. Demirkan I, Williams HF, Dhawi A, et al. Characterization of a spirochaete isolated from a case of bovine digital dermatitis. J Appl Microbiol. 2006;101(4):948-955.

78. Evans JN, Brown I, Demirkan RD, et al. Characterization of novel bovine gastrointestinal tract Treponema isolates and comparison with bovine digital dermatitis treponemes. Appl Environ Microbiol. 2011;77(1):138-147.

79. Brandt S, Apprich V, Hackl V, et al. Prevalence of bovine papillomavirus and Treponema DNA in bovine digital dermatitis lesions. Vet Microbiol. 2010;148(2-4):161-167.
80. Blowey RW. Digital dermatitis control. Vet Rec. 1990;126(5):120.

81. Rodriguez-Lainz A, Melendez-Retamel P, Hird DW, Read DH, Walker RL. Farm- and host-level risk factors for papillomatous digital dermatitis in Chilean dairy cattle. Prev Vet Med. 1992;42(2):87-89.

82. Blowey RW, Sharp MW. Digital dermatitis in dairy cattle. Vet Rec. 1998;122(21):505-508.

83. Laven R, Hunt H. Evaluation of copper sulfate, formalin and peracetic acid in footbaths for treatment of digital dermatitis in cattle. Vet Rec. 2002;151(5):144-146

84. Mumba T, Dopfer D, Kruitwagen C, Dreher M, Gaastra W, van der Zeijst BA. Detection of spirochetes by polymerase chain reaction and its relation to the course of digital dermatitis after local antibiotic treatment in dairy cattle. Zentralbl Veterinarmed B. 1999;46(2):117-126.

85. Hylwa SA, Bury JE, Davis MD, Pittelkow M, Bostwick JM. Delusional infestation, including delusions of parasitosis: results of histologic examination of skin biopsy and patient-provided skin specimens. Arch Dermatol. 2011;147(9):1041-1045.

86. Beausejour A, Deslauriers N, Grenier D. Activation of the interleukin-1beta precursor by Treponema denticola: a potential role in chronic inflammatory periodontal diseases. Infect Immun. 1998;65(8):3199-3202.

87. Jubb KV, Kennedy PC, Palmer N. Pathology of Domestic Animals. 4th ed. New York, NY: Harcourt Brace Javanovich, Academic Press; 1993:531.

88. Kennedy-Crispin M, Billick E, Mitsui H, et al. Human keratinocytes' response to injury upregulates CCL20 and other genes linking innate and adaptive immunity. J Invest Dermatol. 2011. [Epub ahead of print.]

89. Shin JJ, Strle K, Glickstein LJ, Luster A, Steere A. Borrelia burgdorferi stimulation of chemokine secretion by cells of monocyte lineage in patients with Lyme arthritis. Arthritis Res Ther. 2010;12(5):R168.

90. Strle K, Jones KL, Drouin EE, Li X, Steere AC. Borrelia burgdorferi RST1 (OspC Type A) is associated with greater inflammation and more severe Lyme disease. Am J Pathol. 2011;178(6):2726-2739.

91. Cormia F. Syphilitic onychia. Arch Derm Syphilol. 1938;38:432-433.

92. Alessi E, Innocenti M, Ragusa G. Secondary syphilis. Clinical morphology and histopathology. Am J Dermatol. 1983;5:11-17.

93. Zoechling N, Schluepen EM, Soyer HP, Kerl H, Volkenandt M. Molecular detection of Treponema pallidum in secondary and tertiary syphilis. Br J Dermatol. 1997;136(5):683-686.

94. Pereira TM, Fernandes JC, Viera AP, Basto AS. Tertiary syphilis. Int J Dermatol. 2007;46(11):1192-1195.

95. Shawkey MD, Hill GE. Caratenoids need structural colors to shine. Bio Lett. 2005;1(2):121-124.

96. Shawkey MD, Shreekumar RP, Hill GE, Siefferman LM, Roberts SR. Bacteria as an agent for change in structural plumage color: correlational and experimental evidence. Am Nat. 2007;(169 Suppl 1): S112-S121.

97. Eaton MD, Lanyon SM. The ubiquity of avian ultraviolet plumage reflectance. Proc Bio Sci. 2003;270(1525):1721-1726.

98. Hausmann F, Arnold KE, Marshall NJ, Owens IP. Ultraviolet signals in birds are special. Proc Biol Sci. 2003;270(1510):61-67.
Clinical, Cosmetic and Investigational Dermatology

\section{Publish your work in this journal}

Clinical, Cosmetic and Investigational Dermatology is an international, peer-reviewed, open access, online journal that focuses on the latest clinical and experimental research in all aspects of skin disease and cosmetic interventions. All areas of dermatology wil be covered; contributions will be welcomed from all clinicians and

\section{Dovepress}

basic science researchers globally. This journal is indexed on CAS The manuscript management system is completely online and includes a very quick and fair peer-review system, which is all easy to use. Visit http://www.dovepress.com/testimonials.php to read real quotes from published authors. 